\title{
Relationship between G3BP and R4BP with Some Biochemical Parameters in Iraqi Patients with Nonalcoholic Fatty Liver Disease
}

\author{
Hiba Abid Al-Hussein Hassan ${ }^{1}$, Dawood Salman Dawood ${ }^{2}$, Raghad Jawad Hussein ${ }^{3}$ \\ ${ }^{1}$ Assist. Prof. MSC. Biochemistery. Department of Medical Laboratory Science Technology, Collage of Health \\ \& Medical Technology/Baghdad, Middle technical university, Baghdad, Iraq, ${ }^{2}$ Proffersor PhD. Microbiology. \\ Department of Medical Laboratory Science Technology, Collage of Health \& Medical Technology/Baghdad, \\ Middle technical university, Baghdad, Iraq, ${ }^{3}$ Consultant PhD. Gastroenterology and Hepatology Teaching \\ Hospital/Baghdad, Iraq
}

\section{Abstract}

nonalcoholic fatty liver disease starts with liver fat accumulation which is a dangerous factor for disease progression. So, we aimed to determine some biochemical parameters among patients with NAFLD and healthy individuals. Sixty patients with NAFLD and thirtyhealthy control who were attending Gastroenterology and Hepatology Teaching Hospital/Baghdad during the period from August/2019 to March /2020. Which included age, sex, BMI, and abdominal ultrasound result with other medical information. Then all the biochemical test is done by Autoanalyzer, while serum galectin 3 binding protein andserum retinol 4 binding protein measured using ELISAtechnique.Our study found that obesity (70\%) and dyslipidemia $(50 \%)$ were more common in patients with NAFLD than other metabolic diseases. NAFLD subjects showa highly significant elevated $(\mathrm{p}=0.000)$ in the mean $\pm \mathrm{SD}$ of BMI, FBS, HbA1, ALP, triglyceride, VLDL, GGT, and G3BP comparedto the healthy controls. Also,serum ALT, total bilirubin, cholesterol, and RBP4 were highly significantly elevated $(\mathrm{p}=0.001)$ in the mean $\pm \mathrm{SD}$ of NAFLD when compared tomean $\pm \mathrm{SD}$ of healthy control.However, it revealed a significant raise $(\mathrm{P}=0.027)$ in the mean $\pm \mathrm{SD}$ of the serum albumin in the NAFLD patients when compared to the mean \pm SD of the healthy control and a significant elevated $(\mathrm{P}=0.002)$ in the mean $\pm \mathrm{SD}$ of the LDL in the NAFLD patients and healthy control. But showed a significant decrease $(\mathrm{P}=0.029)$ in the mean $\pm \mathrm{SD}$ of the serum HDL of the NAFLD patient when compared tothe mean $\pm \mathrm{SD}$ of the healthy control.Finally, we found that the optimal cut-off value for GGT was $>25$ IU/1 with sensitivity and specificity ( $93.33 \%$ and $70 \%$ ) respectively and RBP4 has an optimal cut-off value $>22.28 \mathrm{ng} /$ $\mathrm{ml}$ with sensitivity and specificity ( $83.33 \%$ and $56.67 \%$ ) respectively. Therefore, the optimal cut-off value was $>9.49 \mathrm{ng} / \mathrm{ml}$ for G3BP with sensitivity and specificity $(93.33 \%$ and $83.33 \%$ ) respectively.

Keywords: Galectin 3 binding protein, Retinol 4 binding protein, nonalcoholic fatty liver disease.

\section{Introduction}

Nonalcoholic fatty liver disease (NAFLD) is one of the most community chronic hepatic diseases and its occurrence is about $25 \%$ of the world-wide ${ }^{1}$. The term "NAFLD" includes a common liver histological change from simple steatosis to steatohepatitis (NASH) and NASH related to fibrosis or cirrhosis ${ }^{2}$. Frequently, NAFLD patients are more probable to be complemented by insulin resistance,obesity, hyper-glycemia, hypertension, and dyslipidemia,therefore NAFLD is believed a liver demonstration of the metabolic syndrome ${ }^{3}$. In addition to obesity and diabetes, the incidence of NAFLD is increasing steadily, progressing to the largest communalreseon of liver diseases in developed countries for adults, teenagers, and infants. A fewresearch on proteins convoluted in NAFLD has so far been addressed ${ }^{4}$. While NAFLD pathogenesis is not well recognized, insulin resistance has long been deemed to play a mainrole in NAFLD production ${ }^{5}$. 
It is less likely that we could find hepatic specific proteins/molecules which can be used in commercial surroundings for identifying fat in the liver. Presently, little importance was being known to the levels ofALT and AST in the diagnosis of hepatic diseases 6,7 . Also, raisedaminotransferase levels in the hepatic function test are a very communal cause for referral of patients to Gastroenterology and/or Hepatology clinics. Identification of NAFLD was dependent on the abnormal concentration of transaminases in greatest of the studies 5 . While there are many inflammation markers, it was difficult to discover hepatic markers that are unique to classic hepatic enzymes such as $\mathrm{ALT}^{6}$. Albumin transfers fatty acids, hormones, and other chemicals, retains oncotic pressure and $\mathrm{pH}$ buffers, among other roles. Other research has shown that NAFLDdysregulated cholesterol metabolism, which may lead to the seriousness of the disease ${ }^{8}$. G3BP is involved in inflammatory distress and immune response. Retinol-binding protein (RBP4) is known as a unique biomarker for insulin resistance and obesity ${ }^{9,11,10}$. Newly identified RBP4 refers to the lipocalin family and is the exact transporter protein for vitamin A in the blood.Itis prominently expressed on the hepatic cell and adipose tissue. In individuals, several studies have found that elevated circulating RBP4 levels were related to obesity, insulin resistance, and diabetes mellitus type $2^{11}$. A recent study found that unusual serum gamma glutamate transferase levels were independently correlated with severe hepatic fibrosis in patients with nonalcoholic fatty liver disease ${ }^{12}$.We should consequently aim to found appropriate prognostic markers rather than accurate diagnostic markers which will assistance to decreased the incidence of liver biopsies to estimate disease development. So we made screening and particular diagnosis of G3BP and R4BP with some biochemical markers in NAFLD

\section{Materials \& Methods}

\section{Patients \& control}

In this prospective study, a total of ninety blood samples were collected from two groups of participants: Group I includes 60 cases of nonalcoholic fatty liver disease patients ages ranged between (20-65 ) years. Group II comprises 30 healthy subjects ages (24-67 ) years who were negative for Hepatitis $\mathrm{C}$ and $\mathrm{B}$ virus by negative enzyme-linked immunosorbent assay (ELISA). Participants were enrolled in Gastroenterology and Hepatology Teaching Hospital during the period from August /2019 to March /2020. A Special form questionnaire includes descriptive information that was designed and filled up for each patient. The questionnaire includes age, sex, abdominal ultrasound result, and other medical information. Weight was measured with a scale. Their heights were also measured by stadiometer. The body mass index was calculated according to weight $(\mathrm{Kg})$ divided by the square of height (meters). Inclusion criteria were based on a negative (ELISA) test for hepatitis $\mathrm{C}$ and $\mathrm{B}$ virus, patients with metabolic disorders ( DM, hypertension, dyslipidemia, and obesity ). An establishment of fatty liver disease was done by abdominal ultrasounds, biochemical tests, and clinical examination by the specialists. The exclusion criteria in this study include patients with no other causes of liver disease, autoimmune, HCC, or co-infection with hepatitis $\mathrm{B}$ and Cvirus and/or human immunodeficiency virus, malignancies, and alcoholic fatty liver disease. This study was agreed by Ethics and Research Committee of the hospital under the supervision of the consultant, while approval for the sampling was got from patients and control.

\section{Biological Samples}

From each individual that was included in this study, $10 \mathrm{ml}$ of the blood sample was drawn by vein puncture using disposable syringes then was centrifuged at $3500 \mathrm{xg}$ for $10 \mathrm{~min}$ and serum was separated from each anticoagulant-free blood sample by centrifugation and was divided into two aliquots; one was immediately used for biochemical tests by SIEMENS Autoanalyzer/ Dimension ${ }^{\circledR}$ Xpand $^{\circledR}$ Plus Integrated Chemistry System /Germany and the other was placed into Eppendorf tubes and frozen at $-20{ }^{\circ} \mathrm{C}$ until used for serum G3BP, serum R4BP, measurement by ELISAtechnique.( all commercial kits were used supplier from Mybiosource / USA)

\section{Statistical Analysis}

Analysis of data was madevia the available statistical package of SPSS-24 (Statistical Packages for Social 
Sciences- version 24). Data were available in simple methods of frequency, percentage, mean, standard deviation, and range.

The significance of the difference of means (quantitative data) was tested using the Students t-test for the difference between two independent means.Receiver Operating Characteristic "ROC" curve technique was used to determine the use of any parameter as a diagnostic or screening tool for disease and the capacity to determine the "cut-off value" which of optimum sensitivity, specificity,positive predictive value(PPV), negative predictive value(NPV), positive likelihood ratio(+LR), negative likelihood ratio (-LR) for diagnosing disease.

\section{Findings}

Characteristics of the NAFLD patients were shown in Table 1 . We found that the percentage of obesity $(70 \%)$ and dyslipidemia (50\%) are more common in NAFLD patients than other metabolic diseases such as hypertension (20\%) which is diagnosed based on if patients are on antihypertensive therapy or their blood pressure is more than $140 / 90 \mathrm{mmHg}$ and diabetes mellitus type 1 and $2(3 \%$ and 30\%) respectively. Also, our study showed that only $20(33.3 \%)$ of NAFLD patients have no sign or symptom while other NAFLD patientshavea weakness (43\%), abdominal pain (40\%), and extreme tiredness $(36.7 \%)$.In addition to the others sign and symptom jaundice (23.3\%), edema (6.7\%), and loss of appetite $(3.3 \%)$.

Table -1: Characteristic of NAFLD patient.

\begin{tabular}{|c|c|}
\hline Parameter & $\begin{array}{c}\text { NAFLD group }(\mathrm{n}=60) \\
\mathrm{n}(\%)\end{array}$ \\
\hline \multicolumn{2}{|l|}{ Type of Metabolic disease } \\
\hline Obesity & $42(70 \%)$ \\
\hline Dyslipidemia & $30(50 \%)$ \\
\hline Hypertension & $12(20 \%)$ \\
\hline DM type 1 & $2(3 \%)$ \\
\hline DM type 2 & $18(30 \%)$ \\
\hline No other metabolic disease & $14(23.3 \%)$ \\
\hline \multicolumn{2}{|l|}{ Sign \& symptom } \\
\hline Extreme tiredness & $22(36.7 \%)$ \\
\hline jaundice & $14(23.3 \%)$ \\
\hline weakness & $26(43.3 \%)$ \\
\hline Abdominal pain & $24(40 \%)$ \\
\hline Loss of appetite & $2(3.3 \%)$ \\
\hline edema & $4(6.7 \%)$ \\
\hline No sign and symptom & $20(33.3 \%)$ \\
\hline
\end{tabular}


While in Table-2 it was observed the age and gender of the studied groups with the comparison of significance. This Table showed that there were 31 male $(51.6 \%)$ and $29(48.3 \%)$ female patients with mean age $(45.03 \pm 12.03)$ years in the NAFLD patients group. While participants
9 male (30\%) and 21 female (70\%) as a healthy control group and the mean age was $(37.40 \pm 12.45)$ years. There was a significant difference among age group $(\mathrm{p}=0.006)$ and no significant difference among gender of these groups were $(\mathrm{P}=0.051)$.

Table -2: Baseline characteristicsof the studied groups according to age and Gender.

\begin{tabular}{|c|c|c|c|c|}
\hline \multicolumn{2}{|c|}{ Variables } & Patients & Healthy Control & P-value \\
\hline \multirow{2}{*}{ 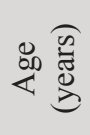 } & Range & $20-65$ & $24-67$ & \multirow{2}{*}{$\begin{array}{l}\mathrm{P}=0.006 \\
\mathrm{~S}(*)\end{array}$} \\
\hline & Mean \pm SD & $45.03 \pm 12.03$ & $37.40 \pm 12.45$ & \\
\hline \multirow{2}{*}{$\stackrel{\mathscr{\Xi}}{0}$} & Male No. (\%) & $31(51.7)$ & $9(30.0)$ & \multirow{3}{*}{$\begin{array}{l}\mathrm{P}=0.051 \\
\mathrm{NS}(* *)\end{array}$} \\
\hline & Female No.(\%) & $29(48.3)$ & $21(70.0)$ & \\
\hline \multicolumn{2}{|c|}{ Total No. } & 60 & 30 & \\
\hline \multicolumn{5}{|c|}{$\begin{array}{l}\text { *Significant difference between proportions using t-test for quality of means at } 0.05 \\
\text { ** nonSignificant difference between proportions using Pearson Chi-square test at } 0.05\end{array}$} \\
\hline
\end{tabular}

Some demographic and biochemical parameters of NAFLD subjects compared tothat of healthy controls showed in Table 3. NAFLD subjects were have a highly significant increased $(\mathrm{p}=0.000)$ in the mean $\pm \mathrm{SD}$ of BMI, FBS , HbA1c , AST,ALP, triglyceride ,VLDL ,GGT and G3BP $\left(31.53 \pm 4.32 \mathrm{~kg} / \mathrm{m}^{2}, 115.09 \pm 25.46 \mathrm{mg} /\right.$ dl $, 6.48 \pm 1.38 \%, 38.23 \pm 13.49 \mathrm{IU} / 1,111.05 \pm 31.14$ $\mathrm{IU} / \mathrm{L}, \quad 172.40 \pm 93.04 \mathrm{mg} / \mathrm{dl} \quad, \quad 34.48 \pm 18.60 \mathrm{mg} / \mathrm{dl} \quad$ ， $73.02 \pm 61.29 \mathrm{IU} / \mathrm{L}$ and $14.46 \pm 3.10 \mathrm{ng} / \mathrm{ml}$ ) respectively comparedtothe healthy controls $\left(22.89 \pm 3.05 \mathrm{~kg} / \mathrm{m}^{2}\right.$ , $85.90 \pm 8.72 \mathrm{mg} / \mathrm{dl}, 4.48 \pm 0.36 \%, 21.17 \pm 5.52 \mathrm{IU} / 1$ ,70.13 $\pm 18.96 \mathrm{IU} / \mathrm{L}, 94.37 \pm 18.30 \mathrm{mg} / \mathrm{dl}, 18.65 \pm 3.41 \mathrm{mg} /$ $\mathrm{dl}, 22.50 \pm 10.10 \mathrm{IU} / \mathrm{L}$ and $8.61 \pm 1.02 \mathrm{ng} / \mathrm{ml}$ ) respectively . Also, shows, according to theWorld Health Organization (WHO) as obesity is defined as a BMI greater than or equal to $30^{2}$, the numerous NAFLD patient was overweight and obesity (17/42 ) respectively. Serum ALT, total bilirubin, cholesterol, and RBP4 were highly significantly elevated $(\mathrm{p}=0.001)$ in the mean \pm SD of NAFLD $(50.12 \pm 22.88 \mathrm{IU} / \mathrm{L}, \quad 14.47 \pm 9.65 \mu \mathrm{mole} / \mathrm{l}$, $193.93 \pm 49.93 \mathrm{mg} / \mathrm{dl}$, and $31.43 \pm 10.75 \mathrm{ng} / \mathrm{ml}$ ) when compared tothe mean \pm SD of healthy control $(21.17 \pm 5.52$ $\mathrm{IU} / \mathrm{L}, \quad 8.01 \pm 2.85 \mu \mathrm{mole} / \mathrm{l}, \quad 156.80 \pm 43.38 \mathrm{mg} / \mathrm{dl}$ and $23.53 \pm 9.73 \mathrm{ng} / \mathrm{ml})$ respectively. Also revealed significant raised $(\mathrm{P}=0.027)$ in the mean $\pm \mathrm{SD}$ of the serum albumin $(4.11 \pm 0.42 \mathrm{~g} / \mathrm{dl})$ in the NAFLD patients when compared tomean $\pm \mathrm{SD}$ of the serum albumin in healthy control $(3.89 \pm 0.45 \mathrm{~g} / \mathrm{dl})$ and significant elevated $(\mathrm{P}=0.002)$ in the mean \pm SD of the LDL $(105.6 \pm 32.63 \mathrm{mg} / \mathrm{dl})$ of the NAFLD patient and healthy control $(85.07 \pm 16.41 \mathrm{mg} / \mathrm{dl})$. But showed a significant decrease $(\mathrm{P}=0.029)$ in the mean $\pm \mathrm{SD}$ of the serum HDL $(42.23 \pm 12.73 \mathrm{mg} / \mathrm{dl})$ of the NAFLD patient when compared tothe mean \pm SD of the healthy control(47.80 $\pm 7.21 \mathrm{mg} / \mathrm{dl})$.While no significant differences between mean \pm SD of the serum urea and creatinine in NAFLD patients and healthy control $(\mathrm{P}=0.903$ and $\mathrm{P}=0.110)$ respectively. 
Table (3): Some demographic and biochemical parameters of studied groups.

\begin{tabular}{|c|c|c|c|}
\hline Parameter & $\begin{array}{c}\text { NAFLD group }(\mathrm{n}=60) \\
\text { Mean } \\
\pm \mathrm{SD}\end{array}$ & $\begin{array}{l}\text { Control group }(\mathrm{n}=30) \\
\text { Mean } \\
\pm \mathrm{SD}\end{array}$ & $\begin{array}{l}\text { t-test for Equality of means } \\
\text { (sig.(2-tailed) }\end{array}$ \\
\hline $\begin{array}{c}\mathrm{BMI}(\mathrm{kg} / \mathrm{m} 2) \\
\text { BMI :normal/overweight/ obese }(\mathrm{N})\end{array}$ & $\begin{array}{c}31.53 \pm 4.32 \\
1 / 17 / 42\end{array}$ & $\begin{array}{c}22.89 \pm 3.05 \\
20 / 0 / 0\end{array}$ & $.000 * * *$ \\
\hline F.B.S (mg/dl) & $115.09 \pm 25.46$ & $85.90 \pm 8.72$ & $.000 * * *$ \\
\hline HbAlc $(\%)$ & $6.48 \pm 1.38$ & $4.48 \pm 0.36$ & $.000 * * *$ \\
\hline AST (IU/l) & $38.23 \pm 13.49$ & $21.17 \pm 5.52$ & $.000 * * *$ \\
\hline ALT(IU/l) & $54.28 \pm 23.05$ & $33.47 \pm 19.05$ & $.001 * * *$ \\
\hline ALP(IU/1) & $111.05 \pm 31.14$ & $70.13 \pm 18.96$ & $.000 * * *$ \\
\hline Total bilirubin $(\mu$ mole/l) & $14.47 \pm 9.65$ & $8.01 \pm 2.85$ & $.001 * * *$ \\
\hline S. Albumin (g/dl) & $4.11 \pm 0.42$ & $3.89 \pm 0.45$ & $.027 *$ \\
\hline S. Cholesterol (mg/dl) & $205.43 \pm 51.19$ & $156.80 \pm 43.38$ & $.000 * * *$ \\
\hline Triglyceride(mg/dl) & $175.05 \pm 91.87$ & $94.37 \pm 18.30$ & $.000 * * *$ \\
\hline HDL (mg/dl) & $34.18 \pm 10.73$ & $47.80 \pm 7.21$ & $.000 * * *$ \\
\hline LDL(mg/dl) & $136.24 \pm 52.81$ & $90.35 \pm 39.99$ & $.000 * * *$ \\
\hline VLDL(mg/dl) & $35.01 \pm 18.37$ & $18.65 \pm 3.41$ & $.000 * * *$ \\
\hline B. urea $(\mathrm{mg} / \mathrm{dl})$ & $27.17 \pm 6.61$ & $26.97 \pm 8.99$ & $.903 *$ \\
\hline S. creatinine $(\mathrm{mg} / \mathrm{dl})$ & $0.84 \pm 0.18$ & $0.78 \pm 0.14$ & $.110^{*}$ \\
\hline GGT (IU/1) & $73.02 \pm 61.29$ & $22.50 \pm 10.10$ & $.000 * * *$ \\
\hline RBP4 (ng/ml) & $31.43 \pm 10.75$ & $23.53 \pm 9.73$ & $.001 * *$ \\
\hline G3BP(ng/ml) & $14.46 \pm 3.10$ & $8.61 \pm 1.02$ & $.000 * * *$ \\
\hline
\end{tabular}

***highly significant $(\mathrm{p}<0.001) * *$ significant $(\mathrm{p}<0.05) \quad *$ non significant $(\mathrm{P}>0.05)$

Recently, ROC analysis has been recommended to calculate the power of serum assays to detect advanced liver disease which table -4 showed AUC , P-value, 95\% confidence interval, optimal cut-off value, sensitivity ,specificity , positive predictive value ,negative predictive value, positive likelihood ratio and negative likelihood ratio for GGT $(0.907,0.000,0.827-0.958$, $>25$ IU/1 , 93.33 ,70\%, PPV86.2\%, NPV84\% , 3.11\% and $0.095 \%$ ) ; RBP4 ( $0.907,0.001,0.602-0.798$, $>22.28 \mathrm{ng} / \mathrm{ml}, 83.33 \%, 56.67 \%$, PPV $81.4 \%$,NPV $60 \%, 1.92 \%$ and $0.92 \%$ ) and G3BP ( $0.958,0.000$ , 0.893-0.989, > 9.49 ng/ml , $93.33 \%, 83.33 \%$,PPV $79.4 \%$, NPV $63 \%, 5.60 \%$ and $0.08 \%$ ) respectively as in Figure -1. 
Table(4): Estimation of ROC analysis with some of the diagnostic testsin the NAFLD and healthy control group.

\begin{tabular}{|l|c|c|c|c|c|c|c|c|c|c|}
\hline Variable(s) & AUC & P-value & $\mathbf{9 5 \%}$ CI & $\begin{array}{c}\text { Cut-off } \\
\text { value }\end{array}$ & $\begin{array}{c}\text { Sensitivity } \\
\mathbf{( \% )}\end{array}$ & $\begin{array}{c}\text { Specificity } \\
\text { (\%) }\end{array}$ & PPV & NPV & +ve LR & -ve LR \\
\hline GGT (IU/l) & .907 & .000 & $.827-.958$ & $>25$ & 93.33 & 70 & 86.2 & 84 & 3.11 & 0.095 \\
\hline RBP4(ng/ml) & .707 & .001 & $.602-.798$ & $>22.28$ & 83.33 & 56.67 & 81.4 & 60 & 1.92 & 0.92 \\
\hline G3BP(ng/ml) & .958 & .000 & $.893-.989$ & $>9.49$ & 93.33 & 83.33 & 79.4 & 63 & 5.60 & 0.08 \\
\hline
\end{tabular}

AUC: Area under curve; CI: Confidence interval; p: Probability for null hypothesis (true area $=0.5$ ), positive predictive value(PPV), negative predictive value(NPV), positive likelihood ratio(+LR), negative likelihood ratio (-LR)

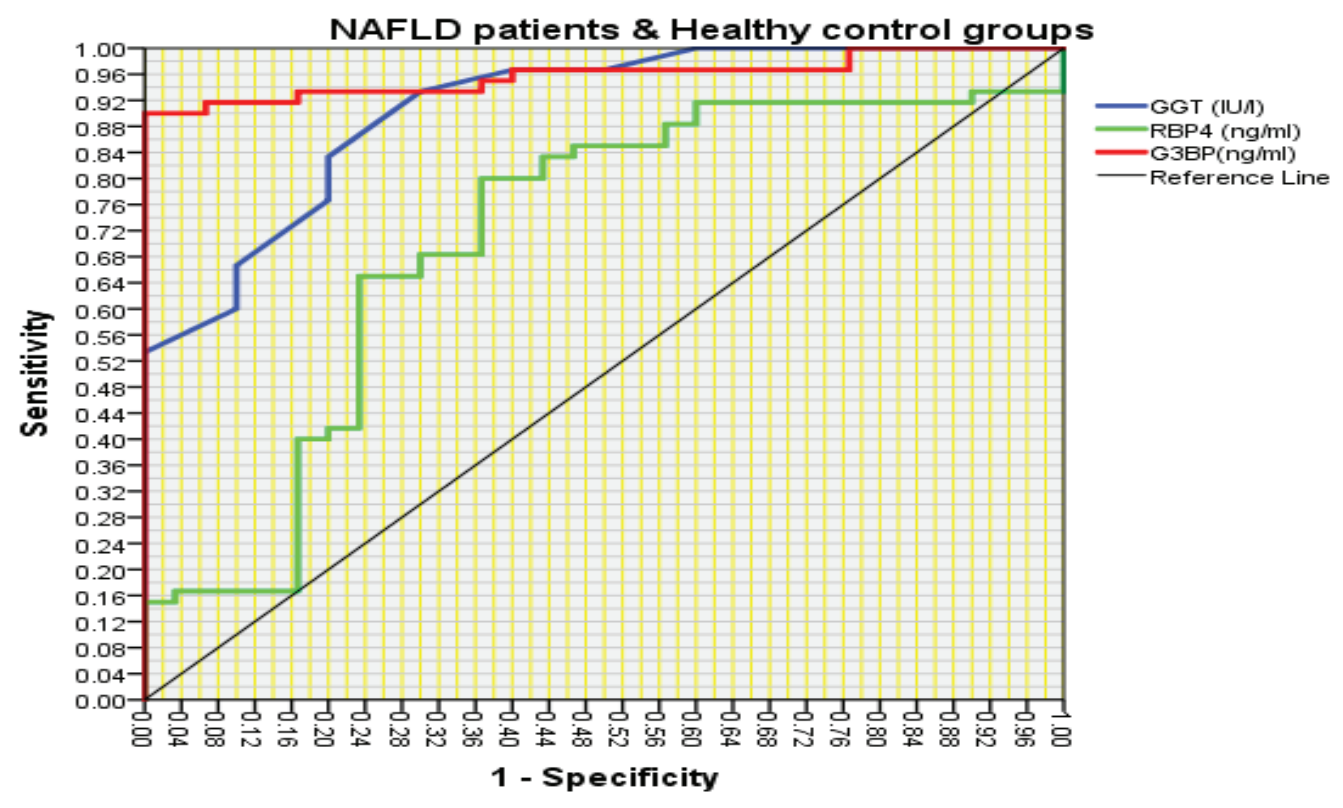

Figure -1: ROC curves estimation for studied parameters in NAFLD and Healthy control group.

\section{Discussion}

NAFLD has become a developing public health problem in recent years and dramatically elevated worldwide $^{13}$. A higher percentage was demonstrated than previous studies which found that $51.34 \%$ of NAFLD patients were suffering from obesity and $22.51 \%$ suffering from diabetes type 2.Beside, the lower percentage was demonstrated than previous studies which found that suffering from dyslipidemia and hypertension were $69.16 \%$ and $39.34 \%$ respectively ${ }^{14}$.Although in NAFLD patients were usually nonspecific their symptom. AlKhater SA. (2015) clinically found that only $42-59 \%$ of NAFLD patients present with abdominal pain ${ }^{15}$.While Khoonsari M et al. (2017) found that fatigue was the common symptom and 
abdominal pain (37.4\%) and loss of appetite $(27.2 \%)^{16}$. In similar to other studies done by Tsuneto A. et al. were found that no gender differences in the development of NAFLD ${ }^{17}$.In similarity with other studies, we found that progress of age leads to an elevated risk of severe liver fibrosis ${ }^{18}$. Thenidentified HbA1c elevated in NAFLD as an increase in intracellular glucose in NAFLD patients ${ }^{19}$.Like other studies done by Sunitha S . et al. which revealed that a highly significant elevated in AST and ALP in NAFLD patients ${ }^{20}$.Furthermore, the highly significant elevation in cholesterol, triglycerides, VLDL, and LDL was observed with significant decreases in HDL levels in patients with NAFLD due to hepaticincreased production of triglyceriderich VLDL particles in fasting conditions in patients with NAFLD leading to insulin decrease VLDL production by inhibiting adipose tissue lipolysis and directly suppressing hepatic production of VLDL, then Insulin fails to inhibit both lipo-lysis and the making of triglyceride rich VLDL particles from the liver.As a result,an increase in VLDL leads to the lowering of HDL cholesterol ${ }^{12,21}$. Also, we observed like other studies several factors that may influence bilirubin-albumin binding affinity such as elevated free fatty acid concentrations leading to decreased binding affinity resulting elevated in serum albumin with total bilirubin $^{22,23}$. Then, we confirmed asignificant associated circulating RBP4 in NAFLD patients asshown by other studies ${ }^{24,25}$. However, we found similarities with studies done by Moon $\mathrm{H}-\mathrm{W}$ et al. which observed that elevated circulating G3BP in chronic liver disease ${ }^{26}$.For the role of GGT as anindicator of metabolic hepatic damage,we demonstrated that GGT activity was a sensitive but nonspecific marker of NAFLD ${ }^{12,27}$. At this moment we found a less result than other studies which found that cut-off serum RBP4 was $26 \mu \mathrm{g} / \mathrm{ml}$ with a sensitivity of $100 \%$ and a specificity of $92.94 \%{ }^{28}$. Finally, our studies have shown that elevated G3BP $>9 \mathrm{ng} / \mathrm{ml}$ was a more sensitive and specific marker for NAFLD patients.In contrast,other studies observed ROC-curves for G3BP in hepatitis C-related fibrosis-grades had 60\% sensitivity and $65 \%$ specificity for the recognition of F2-F4 when levels were above $12.9 \mathrm{mg} / \mathrm{ml}^{29}$. This difference was mostly due to differences in the selection of patients and regional area ......etc.

Conclusions: G3BP was a more sensitive, specific with a high positive likelihood value marker for the diagnosis of NAFLD patients. Also, GGT was a good marker for the diagnosis of NAFLD with less specificity anda high positive likelihood value than RBP4. Finally, we observed that older age, obesity, dyslipidemia, hypertension, and type 2 diabetes were risk factors for NAFLD

Acknowledgment: We are thankful to the staff of Gastroenterology and Hepatology Teaching Hospital/ Baghdadfor their cooperation in providing the clinical specimens during the work in this research.

Ethical Clearance: No need

\section{Source of Funding: None}

Conflict of Interest: The authors have declared no conflict of interest.

\section{References}

1. López-Velázquez JA, Silva-Vidal K V., PoncianoRodríguez G, et al. The prevalence of nonalcoholic fatty liver disease in the Americas. Ann Hepatol. 2014;13(2):166-178. doi:10.1016/s16652681(19)30879-8

2. Younossi ZM. Non-alcoholic fatty liver disease - A global public health perspective. $J$ Hepatol. 2019;70(3):531-544. doi:10.1016/j. jhep.2018.10.033

3. Hashimoto E, Taniai M, Tokushige $\mathrm{K}$. Characteristics and diagnosis of NAFLD/NASH. $J$ Gastroenterol Hepatol. 2013;28:64-70.

4. Younossi Z, Anstee QM, Marietti M, et al. Global burden of NAFLD and NASH: trends, predictions, risk factors and prevention. Nat Publ Gr. 2017;15(1):11-20. doi:10.1038/nrgastro.2017.109

5. Swain M, Nath P, Parida PK, et al. Biochemical Profile of Nonalcoholic Fatty Liver Disease Patients in Eastern India with Histopathological Correlation. Indian J Clin Biochem. 2017;32(3):306-314. doi:10.1007/s12291-016-0612-7

6. McLernon DJ, Donnan PT, Sullivan FM, et al. Prediction of liver disease in patients whose liver function tests have been checked in primary care: model development and validation using population-based observational cohorts. BMJ 
Open. 2014;4(6).

7. Rinella ME. Nonalcoholic fatty liver disease a systematic review. JAMA - J Am Med Assoc. 2015;313(22):2263-2273. doi:10.1001/ jama.2015.5370

8. Min H-K, Kapoor A, Fuchs M, et al. Increased hepatic synthesis and dysregulation of cholesterol metabolism is associated with the severity of nonalcoholic fatty liver disease. Cell Metab. 2012;15(5):665-674.

9. Cai H, Lu S, Chen Y, Das S, Mrcog M, Niu Z. Serum retinol binding protein 4 and galectin-3 binding protein as novel markers for postmenopausal nonalcoholic fatty liver disease. Clin Biochem. 2018;56(December 2017):95-101. doi:10.1016/j. clinbiochem.2018.04.017

10. Yilmaz Y, Eren F, Kurt R, et al. Serum galectin-3 levels in patients with nonalcoholic fatty liver disease. Clin Biochem. 2011;44(12):955-958. doi:10.1016/j.clinbiochem.2011.05.015

11. Gleissner CA, Erbel C, Linden F, et al. Galectin-3 binding protein, coronary artery disease and cardiovascular mortality: Insights from the LURIC study. Atherosclerosis. 2017;260:121-129. doi:10.1016/j.atherosclerosis.2017.03.031

12. Shukla A, Kapileswar S, Gogtay N, et al. Simple biochemical parameters and a novel score correlate with absence of fibrosis in patients with nonalcoholic fatty liver disease. Indian $J$ Gastroenterol. 2015;34(4):281-285. doi:10.1007/ s12664-015-0580-5

13. Yang $\mathrm{T}, \mathrm{Hu} \mathrm{L}, \mathrm{Li} \mathrm{Z}$, et al. Liver Resection for Hepatocellular Carcinoma in Non-alcoholic Fatty Liver Disease : a Multicenter Propensity Matching Analysis with HBV-HCC. Published online 2018.

14. Younossi ZM, Koenig AB, Abdelatif D, Fazel Y, Henry L, Wymer M. Global epidemiology of nonalcoholic fatty liver disease-meta-analytic assessment of prevalence, incidence, and outcomes. Hepatology. 2016;64(1):73-84.

15. Alkhater SA. Paediatric non-alcoholic fatty liver disease: An overview. Obes Rev. 2015;16(5):393405. doi:10.1111/obr.12271

16. Khoonsari M, Azar MMH, Ghavam R, et al. Clinical manifestations and diagnosis of nonalcoholic fatty liver disease. Iran J Pathol. 2017;12(2):99.

17. Tsuneto A, Hida A, Sera N, et al. Fatty liver incidence and predictive variables. Hypertens Res. 2015;33(January 2010):638-643. doi:10.1038/ hr. 2010.45

18. Coppell KJ, Miller JC, Gray AR, Schultz M, Mann JI, Parnell WR. Obesity and the extent of liver damage among adult New Zealanders: findings from a national survey. Obes Sci Pract. 2015;1(2):67-77.

19. Zhou J, Liu J, Sheng H, et al. Haptoglobin 2-2 Genotype is Associated with More Advanced Disease in Subjects with Non-Alcoholic Steatohepatitis: A Retrospective Study. Adv Ther. 2019;36(4):880-895. doi:10.1007/s12325-01900902-Z

20. Sunitha S, Gandham R, Wilma DS, Rao S. Evaluation of significance of liver enzymes as screening tests for the early detection of clinically asymptomatic non alcoholic fatty liver disease in type 2 diabetes mellitus patients. Int $J$ Biomed $A d v$ Res. 2015;6(12):860-863.

21. Idzior-waluś B. Nonalcoholic fatty liver disease is associated with low HDL cholesterol and coronary angioplasty in patients with type 2 diabetes. Published online 2013:1167-1172. doi:10.12659/ MSM.889649

22. Jalan R, Schnurr K, Mookerjee RP, et al. Alterations in the functional capacity of albumin in patients with decompensated cirrhosis is associated with increased mortality. Hepatology. 2009;50(2):555564.

23. Chang Y, Ryu S, Zhang Y, et al. A cohort study of serum bilirubin levels and incident non-alcoholic fatty liver disease in middle aged Korean workers. PLoS One. 2012;7(5):e37241.

24. Baik SH, Choi DS, Kim SG, et al. Serum retinolbinding protein 4 levels are elevated in nonalcoholic fatty liver disease. Clin Endocrinol (Oxf). 2008;68(4):555-560. doi:10.1111/j.13652265.2007.03072.x

25. Liu $\mathrm{Y}, \mathrm{Mu} \mathrm{D}, \mathrm{Chen} \mathrm{H}$, et al. Retinol binding protein 4 induces hepatic mitochondrial dysfunction and promotes hepatic steatosis. J Clin Endocrinol Metab. 2016;101(August):1-11. doi:10.1210/ jc. $2016-1320$ 
26. Moon H-W, Park M, Hur M, Kim H, Choe WH, Yun Y-M. Usefulness of enhanced liver fibrosis, glycosylation isomer of Mac-2 binding protein, galectin-3, and soluble suppression of tumorigenicity 2 for assessing liver fibrosis in chronic liver diseases. Ann Lab Med. 2018;38(4):331-337.

27. Franzini M, Fornaciari I, Fierabracci V, et al. Accuracy of b-GGT fraction for the diagnosis of non-alcoholic fatty liver disease. Liver Int. 2012;32(4):629-634.
28. Nobili V, Alkhouri N, Alisi A, et al. Retinol-binding protein 4: a promising circulating marker of liver damage in pediatric nonalcoholic fatty liver disease. Clin Gastroenterol Hepatol. 2009;7(5):575-579. doi:10.1016/j.cgh.2008.12.031

29. Cheung KJ, Libbrecht L, Tilleman K, Deforce D, Colle I, Van Vlierberghe H. Galectin-3-binding protein: a serological and histological assessment in accordance with hepatitis C-related liver fibrosis. Eur J Gastroenterol Hepatol. 2010;22(9):10661073. doi:10.1097/MEG.0b013e328337d602 